\title{
HEARING DISORDERS AND AUDITORY SPEECH PROCESSING DIFFICULTIES IN ADULTS WITH DOWN SYNDROME: A REVIEW OF THE LITERATURE
}

\author{
Marjolein C. Coppens-Hofman'1, Ben A. M. Maassen ${ }^{1,2}$, \\ Henny M.J. van Schrojenstein Lantman-de Valk ${ }^{3}$, Ad F.M. Snik ${ }^{4}$ \\ ${ }^{1}$ Radboud University Nijmegen Medical Centre - Department of Medical Psychology, Child Neurology Centre \\ and NCEBP \\ ${ }^{2}$ University of Groningen, Centre for Language and Cognition (CLCG) \\ ${ }^{3}$ Radboud University Nijmegen Medical Centre - Department of Primary and Community Care \\ ${ }^{4}$ Radboud University Nijmegen Medical Centre - Department of Otorhinolaryngology and Donders Institute for \\ Brain, Cognition and Behaviour
}

This paper was presented at the EFAS Conference 2011, Warsaw

Corresponding author: Marjolein C. Coppens-Hofman, Radboud University Nijmegen Medical Centre Department of Medical Psychology, Child Neurology Centre and NCEBP, e-mail: M.Coppens@mps.umcn.nl

\begin{abstract}
A literature search was performed to review published articles on hearing disorders, auditory perceptual disorders and shortterm memory in adults with Down syndrome. The aim of the review was to identify factors determining impairments in these domains in order to improve care. A high prevalence was reported for hearing disorders in adults with Down syndrome. The syndrome appears to be an important determinant of communication difficulties, and it appears that auditory memory is related to speech and language skills. However, only a few studies have been published on diagnosis and intervention. The effects of hearing aids use are not always satisfying, but recent developments show promising alternatives. Suggestions are formulated to guide new research that could lead to better care concerning hearing difficulties.
\end{abstract}

\section{НАРУШЕНИЯ СЛУХА И ТРУДНОСТИ ПОНИМАНИЯ РЕЧИ НА СЛУХ У ВЗРОСЛЫХ С СИНДРОМОМ ДАУНА: ОБЗОР ЛИТЕРАТУРЫ}

Содержание этой рукописи было представлено на конференции EFAS 2011 в Варшаве

Резюме

Литературный поиск был выполнен для обзора опубликованных статей на тему расстройств слуха, слуховых нарушений перцепционного типа и краткосрочной памяти у взрослых с синдромом Дауна. Целью обзора является установление факторов, определяющих нарушения в этих областях для улучшения опеки. Большое значение было выделено нарушениям слуха у взрослых с синдромом Дауна, который является важным определяющим фактором коммуникационных трудностей, а слуховая память показывает отношение речи и языковых навыков. Однако существует достаточно маленькое количество публикаций по диагностике и вмешательстве. Эффекты использования слуховых аппаратов не всегда удовлетворительны, но недавнее развитие в данной области представляет обещающие альтернативы. Целью свормулированных предложений является помощь при новых исследованиях, которые могли бы привести к лучшей опеке относительно трудностей со слухом.

\section{LOS DESÓRDENES DEL OÍDO Y LAS DIFICULTADES DE LA COMPRENSIÓN AUDIATIVA DE HABLA EN EL CASO DE ADULTOS CON EL SÍNDROME DE DOWN: UNA REVISIÓN DE LA LITERATURA}

El contenido de este manuscrito fue presentado en la conferencia EFAS 2011, en Varsovia

Extracto

Una búsqueda de literatura fue realizada para examinar los artículos publicados sobre el tema de los desórdenes del oído, los trastornos perceptuales auditivos y de memoria a corto plazo en adultos con el síndrome de Down. El objetivo de la revisión 
es identificar factores que determinan los daños en estas esferas para mejorar el cuidado. Una gran atención fue prestada a los desórdenes del oído en adultos con el síndrome de Down que aparece un determinador importante de dificultades comunicativas y memoria auditiva muestra relaciones con la habla y conocimiento de la lengua. Sin embargo, hay bastante pocas publicaciones en diagnóstico e intervención. Los efectos del uso de audífonos no son siempre satisfactorios, pero el reciente desarollo en este esfera presenta las alternativas prometedoras. El objetivo de las proposiciónes formuladas es la ayuda en las nuevas investigaciónes que podrían llevar al mejor cuidado en los casos de las dificultades auditivas.

\section{Background}

To have the best chances in life, communication skills need to be optimal, but of all people with Down syndrome (DS), 66-89\% have some level of hearing loss in one ear or both ears due to anatomical abnormalities (National Institute on Deafness and other Communication Disorders - NIDCD [1]). Also, many individuals with DS are suffering from other difficulties in their communication, such as speech difficulties causing poor intelligibility and difficulties with auditory speech perception (Roberts, 2007 [2]). Worldwide, 13.65 out of every 10,000 births have Down syndrome (Centres for Disease Control and Prevention and Department of Health and Human Services). It is the most common genetic aetiology of intellectual disabilities. Down syndrome is a genetically based disorder arising from abnormalities of chromosome 21. Trisomy 21 is the most common (about 95\%) karyotype.

Given that $97 \%$ of the people with DS use speech as their main form of communication and given also that speech production and perception difficulties may limit community participation (Roberts, Price \& Malkin [2]) there is major need to develop assessment tools and rehabilitation opportunities for people with DS with speech perception problems (Roberts et al. [2], Evenhuis, van Zanten, Brocaar \& Roerdinkholder [3], Buckley [4]).

A longitudinal study performed by the University of Wisconsin-Madison showed that persons with Down syndrome benefit from language intervention programs during adolescence and adulthood (Chapman, Hesketh $\&$ Kistler [5]). Their language skills continued to improve well beyond the teenage years, although at a reduced pace, which suggests that specific training of adults with DS is beneficial. Optimal hearing is essential in speech-language development and for improving language skills.

In order to find starting points to improve the auditory abilities of adults with DS, our aim was to review the literature and evaluate suggestions for further research into this specific health-care field. Most of the research on hearing and speech in persons with DS has been performed only in children, leaving out knowledge on adults. But adults have a particular place in society and, for them, social contacts at home and work are crucial. This review focuses on hearing loss in adults with DS and the effect of hearing loss on communication.

For this review we collected information on adults with DS and the prevalence and types of hearing loss, auditory perception problems and auditory memory difficulties, as well as treatment of hearing loss using hearing devices.

\section{Methods}

PubMed and Scopus literature searches were conducted for the period from 1988 until 2010. We derived search terms from the International Classification of Functioning, Disability and Health and MeSH. The search terms were combined with 'Down syndrome' and 'Down's syndrome' and limited by 'adults' and 'English' (being the language published in). The exact search terms we used were: hearing, hearing disorders, rehabilitation of hearing impaired, hearing aids, auditory perception, auditory perceptual disorders, speech perception and short-term memo$r y$. Short-term memory has a clear influence on auditory processing (Vicari, Carlesimo \& Catagirone [6]), therefore we decided to include articles on short-term memory.

Exclusion criteria were defined in advance. Articles describing data on children only, articles about other syndromes than DS, articles addressing only a different topic and single case reports were excluded. In Table 1 an overview of inclusions and exclusions of found articles is given.

A total of 124 titles came up on requested search terms of which we could use 51 titles because of the above-described exclusions. From these 51 titles some appeared to come up on different search terms: nine articles came up on two search terms, three articles came up on three different search terms and four titles appeared even on four search lists. Thus, 51-21 = 30 unique titles were used in this review.

Section 1 describes our findings on hearing impairment, its prevalence and types of hearing loss, consequences of hearing loss and auditory memory-related issues. Section 2 discusses treatment options for hearing loss and auditory processing disorders as well as more recent developments in rehabilitation. Section 3 concludes with a discussion and questions for further research.

\section{Hearing impairment and auditory speech pro- cessing disorders in adults with DS}

\subsection{Prevalence}

Hearing impairment is much more common in persons with DS than in the general population. The high incidence of hearing impairment in persons with DS (children and adults) has been well-documented in many studies (for example in Roizen, Wolters, Nicol \& Blondis [7] van Schrojenstein Lantman de Valk, Haveman \& Crebolder [8], Evenhuis et al. [9]). Hearing function of 35 institutionalized persons with DS, age 35 to 62 years, was assessed by means of otoscopy, impedance audiometry, brainstem evoked response audiometry, and pure tone audiometry 
Table 1. Overview of inclusions and exclusions of found articles.

\begin{tabular}{|c|c|c|c|c|}
\hline Search term & $\begin{array}{l}\text { Number of } \\
\text { titels found }\end{array}$ & $\begin{array}{c}\text { Not } \\
\text { included }\end{array}$ & Reasons for exclusion & $\begin{array}{c}\text { Titles } \\
\text { included }\end{array}$ \\
\hline Hearing & 12 & 3 & $\begin{array}{l}\text { 1: Addressing dementia } \\
\text { 1: Describing mixed group } \\
\text { 1: Addressing children only }\end{array}$ & 9 \\
\hline Hearing disorders & 31 & 23 & $\begin{array}{l}\text { 23: Addressing irrelevant topics (dental care in children, } \\
\text { otodystrophic lesions) }\end{array}$ & 8 \\
\hline $\begin{array}{l}\text { Hearing } \\
\text { rehabilitation }\end{array}$ & 7 & 3 & 3: Addressing irrelevant topics (dementia, signing) & 4 \\
\hline Hearing aids & 5 & 0 & & 5 \\
\hline Auditory perception & 50 & 31 & $\begin{array}{l}\text { 13: Addressing children only } \\
\text { 13: Addressing irrelevant topics (dementia, aphasia, } \\
\text { bimanual coordination, glucose, speech production, } \\
\text { music or behavioural disturbances) } \\
\text { 4: Addressing other syndromes only } \\
\text { 1: Case-study }\end{array}$ & 19 \\
\hline $\begin{array}{l}\text { Auditory perceptual } \\
\text { disorders }\end{array}$ & 1 & 0 & & 1 \\
\hline Speech perception & 8 & 6 & $\begin{array}{l}\text { 2: Addressing children only } \\
\text { 3: Addressing irrelevant topics (behaviour test, manual } \\
\text { praxis and dementia) } \\
\text { 1: Describing mixed group }\end{array}$ & 2 \\
\hline Short-term memory & 10 & 7 & $\begin{array}{l}\text { 4: Addressing irrelevant topics (behaviour test and } \\
\text { dementia) } \\
\text { 3: Addressing children only }\end{array}$ & 3 \\
\hline Subtotal & 124 & 53 & & 51 \\
\hline
\end{tabular}

by Evenhuis et al. [9]. In this study hearing losses of $20 \mathrm{~dB}$ to over $90 \mathrm{~dB}$ in 56 of 70 tested ears were found. Schrojenstein et al. [10] reported a somewhat better result: hearing loss was reported in $28 \%$ of adults with DS at the age of 50. Significant hearing loss and external pinna malformations are two of the most common defects evident in DS according to Mazzoni, Ackley \& Nash [11].

The major type of hearing loss in DS is conductive in nature, originating from malformations of the middle ear oscicles and/or the Eustachian tube (Mazzoni et al. [11]). In many cases, more or less permanent hearing loss is caused by OME (glue ear) and impacted wax. Meuwese-Jongejeugd et al. [12] reported that in $26 \%$ of the adults with DS at the Dutch Institutes, hearing thresholds exceeded $40 \mathrm{~dB}$, while $31 \%$ had hearing thresholds of $26-40 \mathrm{~dB}$, indicating mild hearing loss. They also reported that the indicence of hearing impairment in persons with DS was much higher than in the rest of their study population. According to Evenhuis et al. [9] the prevalence rose to $100 \%$ when subjects had reached the age of 60 years. Van Schrojenstein Lantman-de Valk, Haveman \& Crebolder [10] found that in general people with severe or profound mental handicap aged 50 years or older rarely use hearing aids (including older persons with DS). Apparently, there is still very little awareness in caregivers with respect to hearing acuity in adults with DS, particularly based on the observation that these more recent data are no better than those published already many years before (Davies [13], and for data on use of hearing aids on children: Roizen et al. [7]).

\subsection{Types of hearing loss}

Hearing loss found in persons with DS can be conductive, sensorineural or a combination of these two, a so-called mixed hearing loss.

\section{Conductive hearing loss}

A source of recurrent middle ear problems leading to a conductive hearing loss is non-inflammatory otitis media with effusion ("glue ear") that is caused by the accumulation of mucoid secretion (cerumen) in the middle ear, which prevents the middle ear oscicles from moving freely. The Eustachian tube plays a role in the clearance of the middle ear, but its function might be impaired by frequent upper airway infections in persons with DS (Shott [14]). An extra complication is that in persons with DS the cerumen tends to be more copious than usual. As a consequence, the clearing mechanism of the Eustachian tube cannot easily remove the cerumen. Classic medical treatment, such as surgery with suction-removal of the cerumen and the placement of a ventilation tube in the tympanic membrane might be complicated by the narrow ear canals in persons with DS (Shott [14]). Cerumen might in this situation lead to reversible conductive hearing loss of up to $40 \mathrm{~dB}$ HL (Davies [13]). A contributing cause for the high frequency of the remaining middle ear problems is that the immune system in persons with DS develops more slowly, and predisposes these persons to a higher risk of acute middle ear infections and upper respiratory tract infections (Davies [13]). 


\section{Sensorineural hearing loss}

The incidence of permanent congenital inner ear hearing loss in children with DS is much higher than the 1:1000 in the general population. Degenerative cochlear changes are likely to develop from adolescence onwards and most of the adults with DS will have significant sensorineural hearing loss by the age of 40 years (Evenhuis [15]). Buchanan [16] also studied sensorineural hearing loss and reported that DS was associated with early onset presbyacusis, which is supported by the fact that the median sensorineural hearing loss of subjects with DS aged 30 to 40 years was comparable with the general population aged 60 to 70 years. This typically progressive sensorineural hearing loss in the high frequency domain gradually spreads to the middle and lower frequencies more and more with ageing, and has been referred to as 'early presbyacusis' (Buchanan [16]).

\subsection{Auditory perceptual disorders}

Auditory perception is the ability to identify, organize and interpret the sensory input received through hearing. People with auditory perceptual problems (not only people with DS) cannot recognize subtle differences between sounds in words, even though the sounds are presented loud and clear. The cause of this impairment is often unknown. Auditory processing might be impaired in DS, particularly auditory discrimination (the ability to discriminate between speech tokens or between words that sound similar or different), and auditory memory (the ability to accurately remember an auditory stimulus), even in persons with DS who have normal hearing (Marcell, Harvey \& Paige Cothran [17]).

Research by Bunn, Welsh, Simon, Howarth \& Elliott [18] showed that adults with DS did not tend to exhibit the typical right ear - left hemisphere advantage for the perception of speech sounds (although the manifestation of lateral ear advantages might be a confound due to the response paradigm). This was confirmed in dichotic listening tasks and by MRI studies (Bunn et al. [18]). Any disruption or reversal in cerebral specialisation of the left hemisphere of the brain for speech perception in combination with poor specialization of the left hemisphere for speech production and the organization of general movements may contribute to the difficulties found (Elliott, Gray \& Weeks [19]), because combining speech perception with organization and control of speech movements requires good interaction between the two hemispheres. A breakdown of this complex situation could lead to loss or degradation of information (Bunn et al. [18]).

Research indicated that pre-attentive auditory processing underlying stimulus detection was impaired in persons with DS (Pekkonen, Osipova, Sauna-Aho \& Arvio [20]). Unfortunately, no results are available from persons with other types of intellectual developmental disorder to compare with. They also found that parallel auditory processing underlying stimulus detection was impaired in people with DS.

\subsection{Consequences of hearing impairment}

If hearing loss is not treated properly in childhood it can lead to delays in auditory development, speech and language development (Roberts et al. [2]). In the case of long-term hearing difficulties, the situation might become permanent. Consequently, perception of speech elements (such as phonemes) and the coupled fine-tuning of phoneme production may be disturbed, as described in the classic speech perception/production models (Roberts et al. [2]). Inappropriate speech acquisition due to hearing problems is also negatively influenced by the developmental delays inherent to DS and the intellectual disability itself. Poor hearing status is seen as a major cause of the speech difficulties in children and adults with DS (for example in Roberts et al. [2]).

A significant relationship between sentence imitation and middle-ear functioning was supported by analysis in which persons with DS with bilateral abnormal middle ear function tended to perform more poorly on sentence imitation tasks than persons with DS with at least one normal functioning middle ear (Marcell et al. [17]). Abnormal middle ear function is associated with hearing loss. Sentence imitation is a task that is sensitive to the auditory-perceptual, cognitive and expressive difficulties evidenced by individuals with DS (Marcell, Ridgeway, Sewell \& Whelan [21]). The way in which hearing impairment affects behaviour depends on a number of interacting factors, such as the severity of the hearing loss, its duration, the effectiveness of hearing aid fitting, type of hearing loss, age of the subject and the degree of intellectual impairment (Shott et al. [14]). Also, many hearing impaired persons with intellectual disorders such as DS have insufficient coping and compensation strategies. Therefore, they are likely to rely much more on primary sensory input than persons with normal cognition (Roberts et al. [2]). Remarkably, the severity of intellectual disability in persons with DS positive correlates significantly with hearing impairment (including ear disease) in general, and with poor speech production (Määtta et al. [22]).

\subsection{Auditory memory and relations with speech and language skills}

Auditory memory has an important function for storage of incoming language and speech. Recent research into persons with DS and without hearing loss has shown that this specific group shows problems with short-term memory in relation to auditory processing. People with DS have difficulty remembering brief sequences of verbal information presented auditorily. This impairment in (particularly auditory verbal) memory span, sometimes also called poor 'auditory short-term memory for verbal information', plays a role in the production of responses to speech and language tasks. Thus, this may even be a larger contribution to the speech difficulties than a possible hearing impairment itself (Jarrold et al., 2002). Auditory memory span deficits in persons with DS was already confirmed in a study by Bird \& Chapman [23].

Chapman \& Hesketh [24] discussed the significant delay in nonverbal cognitive development accompanied by additional, specific deficits in speech, language production, hearing and auditory short-term memory in infancy and childhood in persons with DS, and also pointed out evidence of dementia emerging for up to half the individuals after age 50 . Problems with short-term memory have direct effect on the understanding of speech, and also on errors in speech production. We will give a brief summary of the studies that discussed this issue in adults with DS. Results of Vicari et al. [6] 
showed a deficit of verbal and spatial backward spans in persons with DS where tasks were offered in forward and backward immediate recall of verbal and spatial sequences. The deficit seemed to be specific for this particular etiology group In general, phonological short-term memory capacity is measured with a word span task, a digit span task, or a nonword repetition task. Bunn et al. [18] administered a test to persons with DS in which they were asked to read, repeat sequences of two or 4 words, and formulate speech from picture sequences. It was found that they tended to make more speech production errors when presented with sequences of words than with sequences of pictures. This illustrates the limited capacity of their auditory short-term memory. Adults with DS and normal hearing made more memory errors than adults with DS and hearing loss. The short-term memory impairment in people with DS has been regarded as an aspect of the behavioural phenotype of DS (Chapman \& Hesketh [24]).

The impairment of auditory short-term memory is thought to contribute to difficulties of language acquisition, speech and cognition even more than hearing impairment (Jarrold, Baddeley \& Phillips [25]). Elliott et al. [19] predicted, based on their studies, that persons with DS would have difficulties with tasks that involve speech perception, organization of movements and control of sequential movements, including speech movements. They based this prediction on their model of neuropsychological evidence in which persons with DS showed atypical right hemispheric speech perception specialization concurrently with left hemispheric motor control specialization. Results of a study of Brock \& Jarrold [26] provided strong evidence that DS is associated with a selective deficit in verbal short-term memory, and a deficit in verbal serial order memory in particular. Vicari [27] compared the memory development and intellectual disabilities between groups of persons with DS, Williams syndrome and normal intelligence. They found that the persons with DS showed distinct memory patterns meaning that there are specific profiles related to DS. People with DS and normal hearing obtained lower explicit memory performance scores than other groups.

Chapman et al. [5] studied whether or not language production and comprehension still is improving in young adults with Down syndrome and the results reflect the fact that expressive language acquisition continues in adolescence. Regarding mentioned findings in literature on the effect of memory on the development of communication skills and the studies of Chapman et al. [5], it seems likely that the learning process of improving communication skills will continue through adolescence and adulthood.

These data confirm the important statement that early and adequate treatment for hearing problems is advisable, followed by specific interventions to improve speech and language development. Also this underscores the need of ongoing care for optimal hearing meaning preventive assessments and optimal hearing rehabilitation.

\section{Rehabilitation of hearing problems in adults with Down syndrome}

With the high prevalence of persisting hearing loss and a relation with difficulties in speech and language, we conclude that rehabilitation of hearing is essential. Treatment starts with screening and testing and when a hearing loss is found, hearing devices might be advised. Shott [14] stated that the incidence of hearing loss in persons with DS can be reduced by taking a vigorous approach to their chronic ear problems. This requires regular screening and timely intervention by the otorhinolaryngologist, which can include ear cleaning, examination, medical and surgical treatment and audiometry to supplement the observations (Evenhuis et al. [28] and Shott [14]).

\subsection{Treatment of hearing loss}

When the hearing loss is permanent, the customary intervention is to fit acoustic hearing aids. Especially in persons with intellectual disabilities and associated impaired linguistic skills, the aim is to provide the best opportunities for communication (Evenhuis et al. [28]). Only little has been published on hearing aid fitting and the few results from studies on hearing aid fitting in adults with DS and hearing impairment are not encouraging. Hearing aid fitting can be troublesome due to subject-related factors, such as insufficient compliance, inability to adapt to the new sensory input, behavioural problems and more (Evenhuis et al. [28]). Evenhuis and coworkers fitted acoustic hearing aids in 9 hearing impaired subjects with DS (it was verified that hearing aids were fitted appropriately). Remarkably, only minor improvements in speech recognition were found after hearing aid provision and the caregivers reported only some fairly subtle improvements. It was concluded that the fitting of hearing aids to treat hearing impairment in persons with DS does not guarantee any improvement in communication. No other studies were found on functional results of acoustic hearing aid fitting in DS.

\section{Treatment for conductive or mixed hearing loss}

Generally, examination (and in many cases ear cleaning) by an otorhinolaryngologist is mandatory in persons with DS and hearing loss. To treat recurrent glue ears, ventilation tubes might be considered (Davies [13]). Unfortunately, the placement of ventilation tubes might be difficult for anatomical reasons in persons with DS (narrow ear canal, tympanosclerosis).

Hearing aid fitting is advised in adults with DS with chronic middle ear problems or chronic conductive hearing loss (Davies [13]; Sheehan \& Hans [29]). Optimizing the person's hearing by fitting them with hearing aids is sometimes difficult owing to variations in the level of conductive hearing loss over time (depending on the middle ear status) and problems with the ear moulds (e.g. feedback) due to the small ear canals. Ear moulds that occlude the ear canal might even have been contra-indicated because of chronic ear infection (Sheehan \& Hans [29]). In such cases, a better option than an acoustic device can be the application of bone-conductor (Sheehan \& Hans [29]) e.g. the Bone Anchored Hearing Aid (BAHA).

\subsection{Bone-conduction hearing aids for treatment of conductive and mixed hearing loss}

Bone-conduction hearing aids transform the incoming sound signals into mechanical vibrations. Special output transducers are pressed against the head in the mastoid 
region and transmit these vibrations to the skull. Vibration of the skull directly stimulates the cochleae to enable hearing. The BAHA device is probably the most effective bone-conduction device on the market (Kunst, Cremers \& Mylanus [30]). Publications on BAHA fitting in persons with DS (Sheehan \& Hans [29]; Kunst, Hol, Snik, Mylanus \& Cremers [31]) show remarkable good results. The BAHA system comprises a percutaneous implant and audio processor (to produce the vibrations) that is coupled directly to the skull. In people with intellectual disabilities, the skin around the percutaneous coupling needs meticulous cleaning and close monitoring. Sheehan and Hans [29] were the first to report on the application of the BAHA in patients with DS and conductive or mixed hearing loss, in whom conventional treatment was not an option. Intensive daily use of the BAHA was reported as well as high patient satisfaction. Only 4 of the 43 subjects experienced serious problems with the implant. Kunst et al. [31] reported on BAHA fitting in 22 patients with intellectual disabilities (mostly adults DS). According to the care providers, all patients were using their BAHA on a daily basis. Problems with the percutaneous implant were scarce. Speech recognition scores had improved to within the normal range and 5 out of the 22 subjects had taken on more demanding daily activities because of the positive effect of the BAHA on their communication abilities (Kunst et al. [31]).

Summarizing, for persons with DS and persistent conductive hearing loss, the BAHA bone conductor seems to be a good option.

\subsection{Treatment for auditory processing disorders}

Treatment programmes for children with delayed auditory development are widely used nowadays, but we found no results of special training programmes for adults with DS.

\section{Discussion and conclusion}

When hearing is optimal, auditory processing can benefit most from interventions and chances for improving communication skills are best. Therefore, we consider it essential to optimize hearing at the earliest possible stage and in all cases.

In adults with DS, it is not always easy to recognize hearing difficulties, because of the general limitations in their communication abilities. Therefore, hearing screening programs are necessary. Worldwide, there are several associations of physicians specialised in treating people with intellectual disabilities. In the early 1990s this association NVAVG (Nederlandse Vereniging van Artsen voor Verstandelijk Gehandicapten) has recommended audiometric screening every 3 years for persons with DS. So far, the NVAVG guidelines have not yet led to reductions in the number of unidentified hearing-impaired subjects in the Netherlands (Evenhuis et al. [9,28], Meuwese-Jongejeugd et al. [12]). Causes of low compliance with hearing screening programs and appropriate follow-up actions include: time constraints by the institute's professionals, lack of information to caregivers, insufficient support from the management team, and the underestimation of the importance of optimal hearing (Meuwese-Jongejeugd et al. [12]).

Several research groups have hypothesized that abnormal cerebral lateralization might underlie the language difficulties that characterize DS. Both hemispheres of the brain are important during the process of speech perception, although the left hemisphere is generally regarded as key; however inter-hemispheric communication is required for tasks that involve a combination of speech perception and the organization and control of limb and oral movements. Based on the articles we found, we can confirm the hypothesis that persons with intellectual disabilities do not show a uniform condition; some cognitive abilities can be disrupted more than others. More research is needed into the field of hearing diagnostics, but most of all into the field of achieving optimal hearing. We still have questions unanswered on hearing and auditory processing problems in adults with DS. For example, how can we provide the best care in hearing impairment for adults with DS? Can auditory memory span and auditory discrimination be improved by training? How to involve caregivers and management in improving communication?

With respect to device fittings and profit of hearing devices, several questions remain: How to improve the acceptance of hearing aids? Which types of therapy might improve the basal auditory skills of adults in general, or after hearing aid fitting, and possibly lead to improvements in speech recognition, speech production and communication? As auditory, speech and language skills are central features in the development of intellectual abilities, such as thinking, reasoning and remembering, as well as in social integration, it is essential that health-care pays close attention to hearing, speech and language throughout early life and into adulthood, in subjects with intellectual disabilities. It is important to stay alert on new developments that are suitable to improve the hearing and speech recognition of persons with Down syndrome.

\section{Declaration of interest}

The authors report no conflicts of interest. The authors alone are responsible for the content and writing of the paper.

\section{References:}

1. NIDCD - National Institute on Deafness and Other Communication Disorders, URL: http://www.nidcd.nih.gov

2. Roberts JE, Price J, Malkin C: Language and communication development in Down syndrome. Ment Retard Dev Disabil Res Rev, 2007; 13: 26-35
3. Evenhuis HM, van Zanten GA, Brocaar MP, Roerdinkholder WHM: Hearing loss in middle-age persons with Down syndrome. Am J Ment Retard, 1992; 97: 47-56

4. Buckley S: Individuals with Down syndrome. Down Syndrome Research and Practice Online, 2002; 8: v-vii 
5. Chapman RS, Hesketh LJ, Kistler DJ: Predicting longitudinal change in language production and comprehension in individuals with Down syndrome: hierarchical linear modeling. J Speech Hear Res, 2002; 45: 902-15

6. Vicari S, Carlesimo A, Caltagirone C: Short-term memory in persons with intellectual disabilities and Down syndrome. J Intellect Disabil Res, 1995; 39(Pt 6): 532-37

7. Roizen NJ, Wolters Ch, Nicol T, Blondis TA: Hearing loss in children with Down syndrome. J Pediatr, 1993; 123: S9-12

8. van Schrojenstein Lantman-de Valk HMJ, Haveman MJ, Crebolder HF: Comorbidity in people with Down syndrome: a criteria-based analysis. J Intellect Disabil Res, 1996; 40(Pt 5): 385-99

9. Evenhuis HM, Theunissen M, Denkers I et al: Prevalence of visual and hearing impairment in a Dutch institutionalized population with intellectual disability. J Intellect Disabil Res, 2001; 45, 457-64

10. van Schrojenstein Lantman-de Valk HMJ, Haveman MJ, Maaskant et al: The need for assessment of sensory functioning in ageing people with mental handicap. J Intellect Disabil Res, 1994; 38(Pt 3): 289-98

11. Mazzoni DS, Ackley RS, Nash DJ: Abnormal pinna type and hearing loss correlations in Down syndrome. J Intellect Disabil Res, 1994; 38(Pt 6): 549-60

12. Meuwese-Jongejeugd A, Vink M, Zanten B van et al: Prevalence of hearing loss in 1598 adults with an intellectual disability: Cross-sectional population based study. Int J Audiol, 2006; 45: 660-69

13. Davies B: Auditory disorders in Down syndrome. Scand Audiol, 1988; Suppl. 30: 65-68

14. Shott, SR: Down Syndrome: common otolaryngologic manifestations. Am J Med Genet C Semin Med Genet, 2006; 142C: $131-40$

15. Evenhuis HM: Medical aspects of ageing in a population with intellectual disability: II. Hearing impairment. J Intellect Disabil Res, 1995; 39: 27-33

16. Buchanan LH: Early onset of presbyacusis in Down syndrome. Scand Audiol, 1990; 19: 103-10

17. Marcell MM, Harvey CF, Paige Cothran L: An attempt to improve auditory short-term memory in Down syndrome individuals through reducing distractions. Res Dev Disabil, 1988; Vol. 9, 405-17

18. Bunn L, Welsh T, Simon DA, Howarth K, Elliott D: Dichotic ear advantages in adults with Down syndrome predict speech production errors. Neuropsychology, 2003; 17(1): 32-38
19. Elliott D, Gray S, Weeks DJ: Cerebral specialization for speech perception and movement organization in adults with Down syndrome. Cortex, 1993; 29, 103-13

20. Pekkonen E, Osipova D, Sauna-Aho, Arvio M: Delayed auditory processing underlying stimulus detection in Down Syndrome. Neuroimage, 2007; 35 1547-50

21. Marcell MM, Ridgeway MM, Sewell DH, Whelan ML: Sentence imitation by adolescents and young adults with Down syndrome and other intellectual disabilities. J Intellect Disabil Res, 1995; 39(Pt 3): 215-32

22. Maatta T, Kaski M, Taanila A et al: Sensory impairments and health concerns related to the degree of intellectual disability in people with Down syndrome. Downs Syndr Res Pract, 2006; 11: 78-83

23. Bird EK, Chapman RS: Sequential recall in individuals with Down syndrome. J Speech Hear Res, 1994; 37: 1369-80

24. Chapman RS, Hesketh LJ: Behavioral phenotype of individuals with Down syndrome. Ment Retard Dev Disabil Res Rev, 2000; 6: 84-95

25. Jarrold C, Baddeley AD, Phillips CE: Verbal short-term memory in Down syndrome: a problem of memory, audition, or speech? J Speech Hear Res, 2002; 45: 531-44

26. Brock J, Jarrold C: Serial order reconstruction in Down syndrome: evidence for a selective deficit in verbal short-term memory. J Child Psychol Psychiatry, 2005; 46: 304-16

27. Vicari S: Memory development and intellectual disabilities, Acta Paediatr, 2004; Suppl. 445: 60-64

28. Evenhuis HM, Lier PA van, Hakker AA et al: Effects of treatment of hearing loss in middle-aged persons with Down syndrome: a pilot study. Int J Disab, Devel Ed, 1993; 40: 159-62

29. Sheehan PZ, Hans PS: UK and Ireland experience of bone anchored hearing aids (BAHA) in individuals with Down syndrome. Int J Pediatr Otorhinolaryngol, 2006; 70: 981-86

30. Kunst SJ, Hol MK, Cremers CW, Mylanus EA: Bone-anchored hearing aid in patients with moderate mental retardation: impact and benefit assessment. Otol Neurotol, 2007; 28: 793-97

31. Kunst SJW, Hol MK, Snik AF et al: Rehabilitation of patients with conductive hearing loss and moderate mental retardation by means of a bone-anchored hearing aid. Otol Neurotol, 2006; 27: 653-58 Centres for Disease Control and Prevention, URL http://www. cdc.gov

Department of Health and Human Services, URL: http://www. hhs.gov 